\title{
Erratum to: Decadal cycling within long-lived carbon pools revealed by dual isotopic analysis of mineral-associated soil organic matter
}

\author{
Sarah L. O'Brien · Julie D. Jastrow • \\ Karis J. McFarlane - Thomas P. Guilderson • \\ Miquel A. Gonzalez-Meler
}

Published online: 8 June 2012

(C) Springer Science+Business Media B.V. 2012

\section{Erratum to: Biogeochemistry DOI 10.1007/s10533-011-9673-0}

The authors regret errors arising from ambiguity in ${ }^{14} \mathrm{C}$-based turnover time calculations. Corrected values are reported in a revised Table 5. These corrections necessitate the following modifications to the text.

In the last paragraph of the Results, hydrolysable silt and clay had turnover times that were generally $<100$ years (not $<5$ years), and the $\Delta^{14} \mathrm{C}$ of brome

The online version of the original article can be found under doi:10.1007/s10533-011-9673-0.

S. L. O’Brien · M. A. Gonzalez-Meler

Department of Biological Sciences, University of Illinois

at Chicago, 845 West Taylor Street M/C 066,

Chicago, IL 60607, USA

\section{S. L. O’Brien $(\square)$}

Institute for Genomics and Systems Biology,

Argonne National Laboratory,

9700 South Cass Avenue, Argonne, IL

60439, USA

e-mail: sobrien@anl.gov

J. D. Jastrow

Biosciences Division, Argonne National Laboratory,

9700 South Cass Avenue, Argonne, IL 60439, USA

\section{K. J. McFarlane · T. P. Guilderson}

Center for Accelerator Mass Spectrometry,

Lawrence Livermore National Laboratory,

7000 East Avenue, Livermore, CA 94551, USA total silt should be $-30 \%$ (not $-33 \%$ ). The authors ask that readers disregard the section in the first paragraph of the Conclusions that states, 'Using our fractionation scheme and the ${ }^{14} \mathrm{C}$-based turnover times, the hydrolysable fraction would be deemed "active". Given that about one quarter of the soil C was hydrolysable, these findings are inconsistent with a prevailing paradigm in some models that the active pool is relatively small $(<10 \%)$ and largely attributable to microbial biomass and readily decomposable microbial products (Di Tizio and Grego 2008; Parton et al. 1988). Furthermore, only the POM fraction would be considered to be an intermediate turnover pool in most soil C models.' 
Table $5 \Delta \Delta^{14} \mathrm{C}$ and ${ }^{14} \mathrm{C}$-derived mean turnover times of mineral-associated soil organic matter pools in 1986 (brome) or 1989 (corn)

\begin{tabular}{|c|c|c|c|c|}
\hline & \multicolumn{2}{|l|}{$\Delta^{14} \mathrm{C}(\%)$} & \multicolumn{2}{|c|}{ Turnover time (years) } \\
\hline & Brome & Corn & Brome & Corn \\
\hline \multicolumn{5}{|l|}{ Silt } \\
\hline Total & $-30 \pm 15$ & -61 & $490 \pm 100$ & 700 \\
\hline Hydrolysable $^{\mathrm{a}}$ & $265 \pm 127$ & 67 & $40 \pm 30$ & 130 \\
\hline $\mathrm{NH}$ & $-170 \pm 74$ & -144 & $1,830 \pm 840$ & 1,460 \\
\hline $\mathrm{NH}-\mathrm{O}^{\mathrm{a}}$ & $-143 \pm 83$ & -121 & $1,560 \pm 870$ & 1,220 \\
\hline NH-NO & $-268 \pm 37$ & -274 & $3,090 \pm 590$ & 3,120 \\
\hline \multicolumn{5}{|l|}{ Clay } \\
\hline Total & $-73 \pm 10$ & -79 & $790 \pm 80$ & 840 \\
\hline Hydrolysable $^{\mathrm{a}}$ & $151 \pm 16$ & 116 & $60 \pm 10$ & 80 \\
\hline $\mathrm{NH}$ & $-156 \pm 11$ & -182 & $1,590 \pm 120$ & 1,890 \\
\hline $\mathrm{NH}-\mathrm{O}^{\mathrm{a}}$ & $-149 \pm 10$ & -176 & $1,520 \pm 110$ & 1,810 \\
\hline NH-NO & $-210 \pm 18$ & -225 & $2,230 \pm 240$ & 2,410 \\
\hline
\end{tabular}

Values for brome are means ( $n=3$, except for hydrolysable, NH, and NH-O silt where $n=2) \pm$ SE. Values for corn represent a single measurement on a composite of three replicates

$\mathrm{NH}$ non-hydrolysable, $\mathrm{NH}$ - $\mathrm{O}$ non-hydrolysable, oxidizable, $\mathrm{NH}$ - $\mathrm{NO}$ non-hydrolysable, non-oxidizable

a Determined by mass balance according to Jagadamma et al. (2010) 